\title{
Diazoxide-Mediated Growth Inhibition in Human Lung Cancer Cells via Downregulation of $\beta$-Catenin-Mediated Cyclin D1 Transcription
}

\author{
Jianyong Ding $\cdot$ Di Ge $\cdot$ Weigang Guo $\cdot$ \\ Chunlai Lu
}

Received: 28 July 2008/ Accepted: 17 October 2008/Published online: 4 December 2008

(c) The Author(s) 2008. This article is published with open access at Springerlink.com

\begin{abstract}
Treatment of various types of cells with the mitochondrial ATP-sensitive $\mathrm{K}^{+}$channel opener, diazoxide, preconditions cells to subsequent injuries and inhibits apoptosis. However, the role and mechanism(s) of diazoxide in solid tumor cell growth are largely unknown. Here we demonstrate that diazoxide inhibited the proliferation of lung cancer cells as well as the transcription of cell cyclerelated protein Cyclin D1. Cyclin D1 overexpression inhibited the negative role of diazoxide in cell cycle progression. We further explored the mechanisms by which diazoxide affected Cyclin D1 transcription and found that the $\beta$-catenin transcription factor was downregulated by diazoxide, with a corresponding decrease in Cyclin D1 promoter activity. Taken together, these results suggest that diazoxide inhibits lung cancer cell proliferation via downregulation of Cyclin D1 transcription, which may have important therapeutic implications in lung cancer patients.
\end{abstract}

Keywords $\beta$-Catenin - Diazoxide · Lung cancer · Cyclin D1 · Transcriptional regulation

\section{Introduction}

In various types of cells, opening of the mitochondrial ATP-sensitive $\mathrm{K}^{+}$(mitoK-ATP) channels leads to enhanced resistance to subsequent injury caused by dif-

J. Ding · D. Ge $(\bowtie) \cdot$ W. Guo · C. Lu

Zhongshan Hospital, Fudan University, Shanghai 200032,

People's Republic of China

e-mail: zs_dige@yahoo.com.cn ferent stimuli, including induction of apoptosis [1-4]. MitoK-ATP channels can be selectively opened using low doses of diazoxide [5]. Diazoxide is a potassium channel activator, which causes local relaxation in smooth muscle by increasing membrane permeability to potassium ions [4-9]. Although the effect of diazoxide on isolated mitochondria has been thoroughly studied, the role and mechanism(s) of diazoxide in solid tumor cell growth are largely unknown. Therefore, the goal of our study was to explore the morphologic and biochemical changes induced by diazoxide in tumor cells and find out how such changes might lead to enhanced prosurvival signaling.

One of the main properties of cancer cells is their increased and deregulated proliferative activity $[10,11]$. It is now well known that abnormalities in many positive and negative modulators of the cell cycle are frequent in many cancer types, including lung carcinomas [12, 13]. Cyclin D1, a member of the Cyclin D family, regulates the initial G1-to-S transition by inhibiting $\mathrm{Rb}$ and activating E2F proteins, and it contributes to cell apoptosis, proliferation, and differentiation [14]. Cyclin D1 is amplified and/or overexpressed in a number of human cancers, including breast carcinoma and $\mathrm{B}$ cell and $\mathrm{T}$ cell malignancies, and contributes to tumor cell growth [14-16]. Accumulated evidence indicates that there is extensive cross-talk between the transcriptional and posttranscriptional regulation of Cyclin D1 expression and its biological functions.

In this study we examined the effect of diazoxide on H1299 cell proliferation. Diazoxide inhibited the proliferation of H1299 cells as well as the transcription of cell cycle-related protein Cyclin D1 via downregulation of $\beta$-catenin transcription factor, which provided a new mechanism of diazoxide-involved cell proliferation and may have important therapeutic implications in lung cancer patients. 


\section{Methods}

Materials

Restriction enzymes, bovine calf serum, RPMI-1640 medium, Trizol reagent, and the mammalian expression vector pcDNA3.0 were from Invitrogen (Carlsbad, CA, USA). Diazoxide and aprotinin were from Sigma Chemical Co (St. Louis, MO, USA). Anti-human-Cyclin D1, anti-humanCyclin D2, anti-human-Cyclin D3, anti-human-CDK4, antihuman-CDK6, and anti-human- $\beta$-catenin antibodies were purchased from Santa Cruz Biotechnology (Santa Cruz, CA, USA). Anti-myc and anti-actin antibodies were purchased from Oncogene (Cambridge, MA, USA). Anti-mouse-HRP secondary antibody and anti-rabbit-HRP secondary antibody were purchased from New England BioLabs (Ipswich, MA, USA). Other reagents were commercially available in China. The enhanced chemiluminescence (ECL) assay was from Amersham Pharmacia Biotech (Uppsala, Sweden). TaKaRa RNA PCR Kit (AMV ver.2.1) and TaKaRa MutanBEST kit were from TaKaRa Bio Inc. (Otsu, Shiga, Japan).

\section{Plasmids}

Expression constructs for EGFPN3, pcDNA3.1-myc-A, pGL3Basic, and pRL-CMV were kindly provided by

Fig. 1 Effect of diazoxide on the proliferation of H1299 cells. a H1299 cells treated with control or diazoxide $(20 \mu \mathrm{M})$ for $24 \mathrm{~h}$ were trypsinized and plated at densities of $2 \times 10^{5}$ into 6-well plates (Day 0). Cell numbers were counted every $24 \mathrm{~h}$. Results represent the mean of at least four independent experiments; $b a r=S E$. $\mathbf{b}$ BrdU uptake assays as an index of DNA synthesis were performed with $\mathrm{H} 1299$ cells treated or not treated with diazoxide $(20 \mu \mathrm{M})$ for $24 \mathrm{~h}$, as described in Methods. Results are expressed as the mean $\pm \mathrm{SD}$ of five independent experiments. c Compared to control, H1299 cells treated with diazoxide $(20 \mu \mathrm{M})$ for $24 \mathrm{~h}$ had a markedly reduced number of cells. d Exponentially growing cells were treated with the indicated concentrations of diazoxide. H1299 cells were stained with propidium iodide and analyzed by flow cytometry $48 \mathrm{~h}$ after diazoxide exposure
Dr. Dan Liu (Shanghai Medical College of Fudan University). Full-length cDNA of Cyclin D1 was generated using PCR with $0.1 \mu \mathrm{g}$ human fetal liver cDNA library as the template, and the primers used were primer 1 (sense) (5'-TATGGAATTCCCCAGCCATGGAA- $\left.3^{\prime}\right)$ and primer 2 (antisense) (5'-TATGGATCCCGCCCTCAGAT- $\left.3^{\prime}\right)$. The PCR product was inserted in-frame into the pcDNA3.1mycA vector via $E c o$ RI and BamHI restriction sites. Clones were sequenced to identify the right insert. A 1800-bp fragment of the human Cyclin D1 promoter was isolated by PCR using $1 \mu \mathrm{g}$ human genomic DNA as the template as previously described [17]. Reporter genes containing sequentially truncated fragments $(-1745 /+18,-963 /+18$, $-680 /+18,-420 /+18,-240 /+18,-160 /+18,-140 /$ +18 , and $-60 /+18$ ) of the Cyclin D1 promoter region were prepared in a similar manner. Cyclin D1 promoter LEF1 binding-site-directed mutagenesis constructs were derived from pGL3(-420/+18) by PCR amplification using TaKaRa MutanBEST mutagenesis kit.

\section{Cell Culture and Transfection}

H1299 cells were purchased from Shanghai Institutes for Biological Sciences and cultured in Dulbecco's modified Eagle's medium. Cell transfection was performed with
B
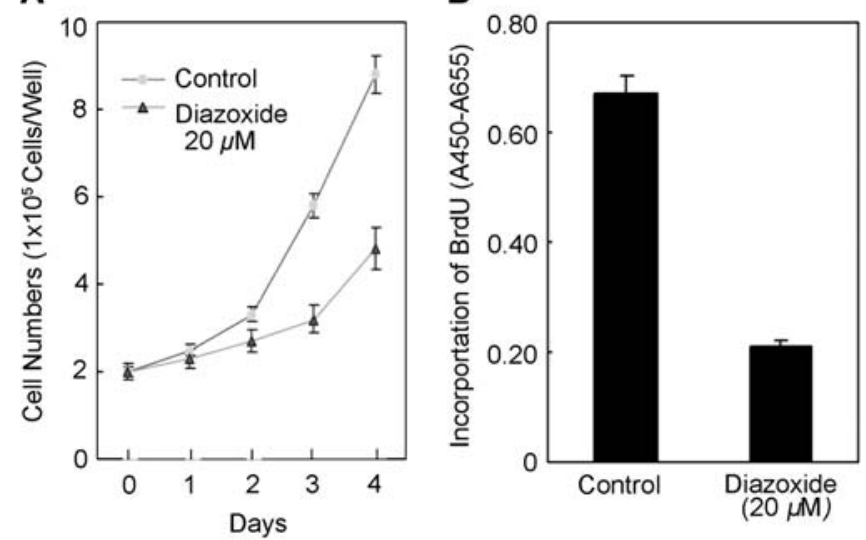

C

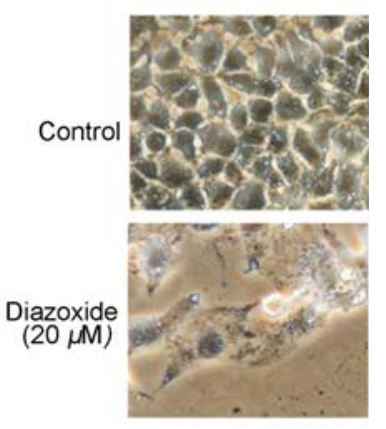

D

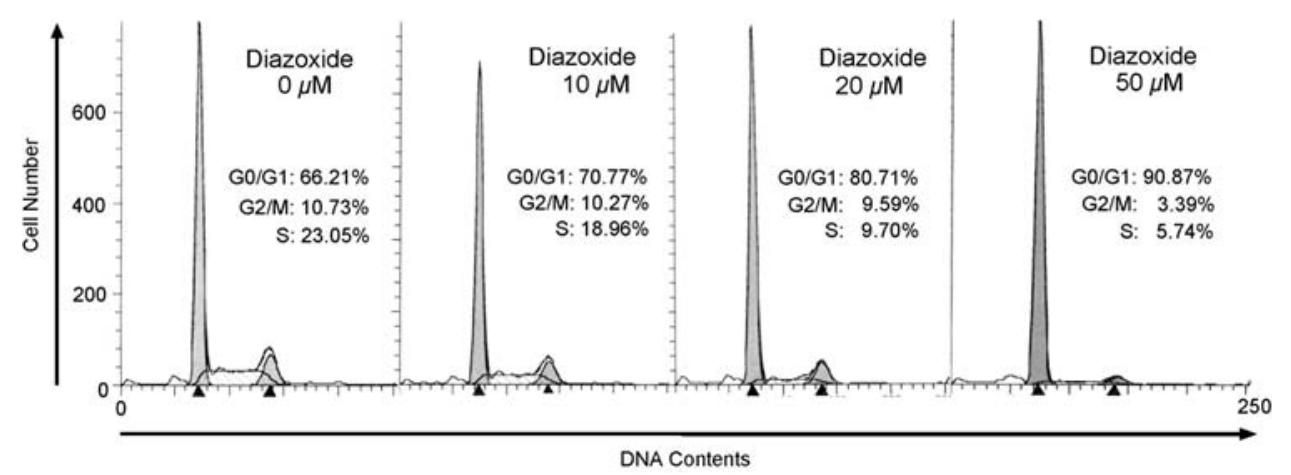


Lipofectamine 2000 (Invitrogen) according to the manufacturer's instructions.

Analysis of Cell Cycle by FACS and Western Blot Analysis

After $48 \mathrm{~h}$ of transfection, adherent and nonadherent cells were collected, washed twice in phosphate-buffered saline (PBS), and fixed with ice-cold $70 \%$ ethanol for at least $1 \mathrm{~h}$. The fixed cells were washed and stained with propidium iodide mixture containing $50 \mu \mathrm{g} / \mathrm{ml}$ propidium iodide, $0.05 \%$ Triton X-100, $37 \mu \mathrm{g} / \mathrm{ml}$ EDTA, and $100 \mathrm{U} / \mathrm{ml}$ ribonuclease in PBS. After incubation for $45 \mathrm{~min}$ at $37^{\circ} \mathrm{C}$, the DNA content was determined by quantitative flow cytometry with standard optics of the FACScan flow cytometer (FACStar, Becton, Dickinson, Franklin Lakes, NJ, USA) as previously reported [18]. Western blot was performed as previously described [19] using an antibody to GAPDH to ensure equivalent loading.
Dual Luciferase Assay and Reverse Transcription (RT)PCR

Dual luciferase assay and reverse transcription (RT)-PCR were performed as described [19]. Primers used for PCR were as follows: Cyclin D1-F, 5'-CCGTCCATGCGGAA GATC-3' and Cyclin D1-R, 5'-ATGGCCAGCGGGAA GAC- $3^{\prime}$.

\section{Results}

Effect of Diazoxide on Cell Proliferation in H1299 Cells

We first examined the effect of diazoxide on the cell proliferation of H1299 cells. Diazoxide dramatically reduced the proliferation rate in a dose-dependent manner compared to untreated cells (Fig. 1a). Consistent with the inhibition of
Fig. 2 Effect of diazoxide on the expression of proteinregulating cell cycle. a Cells treated with diazoxide $(20 \mu \mathrm{M})$ for $24 \mathrm{~h}$ were examined for the expression of molecules regulating apoptosis by Western blot analysis using specific antibodies. GAPDH was used as an internal control. b Cells treated with diazoxide $(20 \mu \mathrm{M})$ for $24 \mathrm{~h}$ were examined for the expression of molecules regulating apoptosis by RTPCR using specific primers. GAPDH mRNA expression was used as an internal control. c H1299 cells were transiently transfected with Cyclin D1 promoter construct pGL3($1745 /+18)$. At $24 \mathrm{~h}$ after transfection, cells were treated with vehicle or an increasing dose of diazoxide for an additional $24 \mathrm{~h}$. The luciferase activity values were standardized to those observed in nontreated samples. Each value is the mean $\pm \mathrm{SD}$ of at least three independent experiments
A

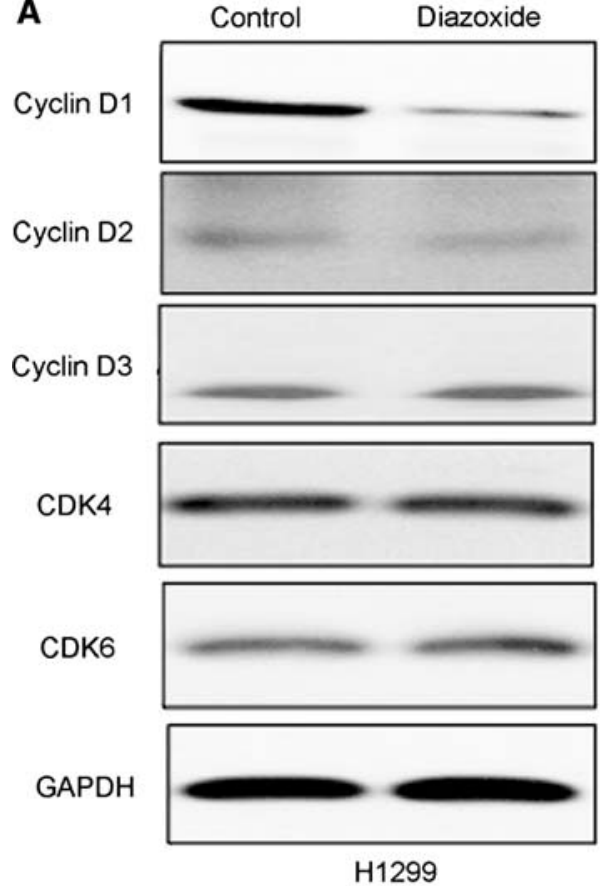

B

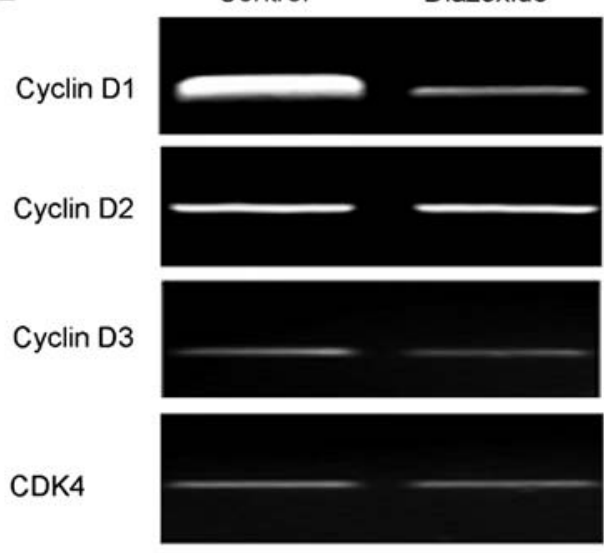

CDK6

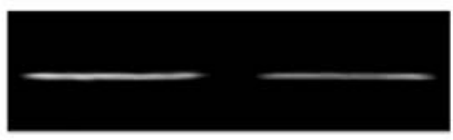

GAPDH

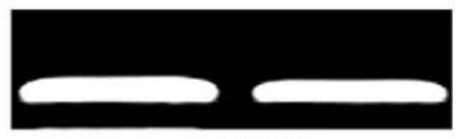

H1299

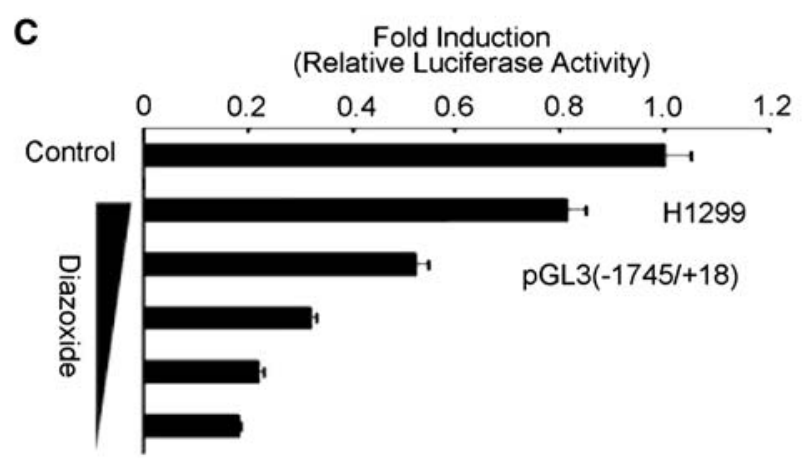


cell proliferation, DNA synthesis, as determined by BrdU incorporation, was also significantly reduced in $\mathrm{H} 1299$ cells treated with diazoxide compared with that of control (Fig. 1b). Compared to control, H1299 cells treated with diazoxide $(20 \mu \mathrm{M})$ for $24 \mathrm{~h}$ had a markedly reduced number of cells (Fig. 1c). The effect of diazoxide on the cell cycle was determined in H1299 cells using FACS analysis. As shown in Fig. 1d, diazoxide induced a G1 phase arrest in a dose-dependent manner (Fig. 1d).

\section{Diazoxide Downregulated Cyclin D1 mRNA Expression}

To address the mechanisms of diazoxide-reduced cell growth, we investigated the effect of diazoxide on the expression of the Cyclin D family proteins (Cyclin D1, D2, and D3) and their corresponding kinases (CDK4 and CDK6), which are involved in the regulation of cell cycle progression and mitogenic signals [14, 20]. As depicted in Fig. 2a, diazoxide downregulated the expression of Cyclin D1 without significantly changing the expression of the other examined proteins. Next, we performed RT-PCR to determine the effects of diazoxide on the mRNA expression of the Cyclin D family, CDK4, and CDK6. As depicted in Fig. 2b, diazoxide inhibited the mRNA expression of Cyclin D1. There were no significant differences in Cyclin D2, Cyclin D3, CDK4, or CDK6 mRNA levels before and after diazoxide treatment. To determine the role of diazoxide in Cyclin D1 transcription, we a constructed Cyclin D1 promoter pGL3 that contained the region from nucleotide position -1745 to +18 relative to the transcription start codon. Transfection studies using pGL3 treated with the indicated dose of diazoxide showed that diazoxide inhibited the activity of the Cyclin D1 promoter in a dose-dependent manner in H1299 cells (Fig. 2c).

\section{Diazoxide Inhibited Cyclin D1 Transcription via Downregulation of $\beta$-Catenin Transcription Factor}

To identify the cis element responsible for the effect of diazoxide, luciferase reporter constructs containing progressive deletion of the 1745-bp genomic DNA fragment were generated and cotransfected into H1299 cells treated or not treated with diazoxide. The luciferase assay showed
A

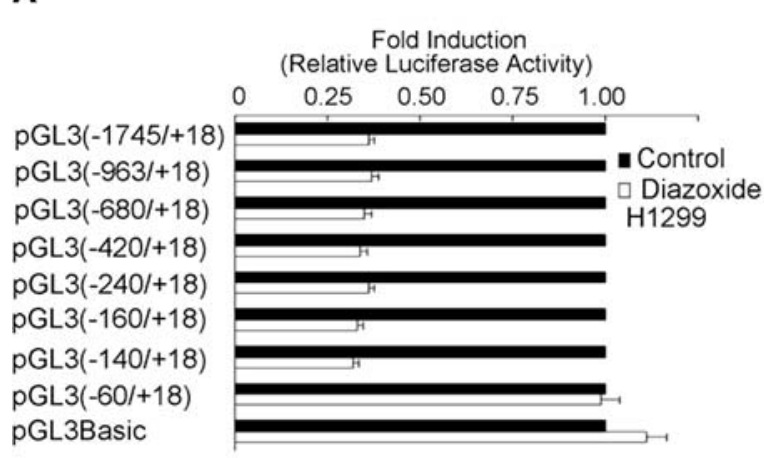

C

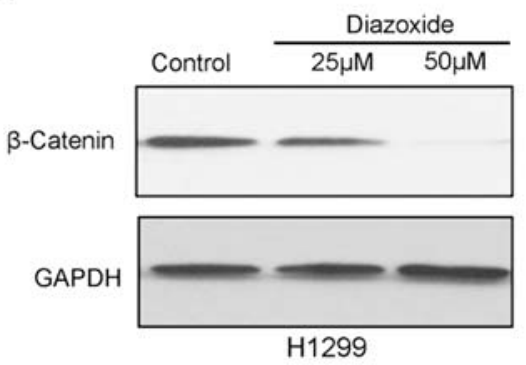

Fig. 3 Diazoxide downregulates Cyclin D1 promoter activity by reducing the level of transcription factor $\beta$-catenin. a Cyclin D1-luc constructs containing various lengths of Cyclin D1 promoter regions were transiently transfected into H1299 cells treated or not treated with diazoxide. Luciferase activities were measured as described above. Normalized luciferase activity was standardized to that with vector alone. b Reporter plasmid pGL3(-420/+21) (WT) or its LEF1 binding-site-mutated constructs (MUT) were transfected into H1299 cells. At $24 \mathrm{~h}$ after transfection, cells were treated with control or
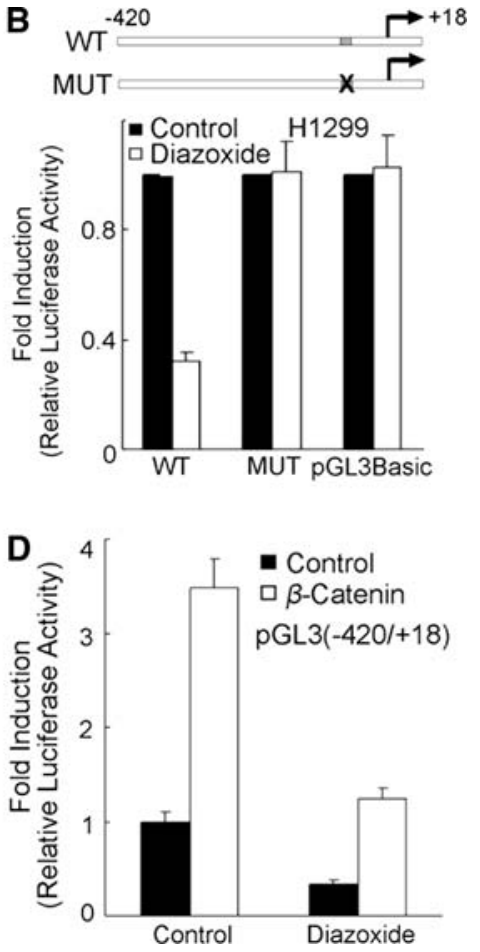

diazoxide for $24 \mathrm{~h}$. The luciferase activities were obtained and presented as described above. c H1299 cells were treated for $24 \mathrm{~h}$ with indicated dose of diazoxide and cell extracts were subjected to immunoblot analysis using an anti- $\beta$-catenin antibody. d H1299 cells were transiently cotransfected with pGL3 $(-420 /+21)$ construct and control vector or $\beta$-catenin expressing vector. At $24 \mathrm{~h}$ after transfection, cells were treated or not treated with diazoxide for $24 \mathrm{~h}$. Normalized luciferase activity was standardized to pGL3 $(-420 /+18)$ with control vector in untreated cells 
that a deletion from -140 to $-60 \mathrm{bp}$ resulted in a loss of diazoxide activation (Fig. 3a).

Cyclin D1 is a key molecule in mitogenic signaling and mediates S-phase entry from the G1 phase in the cell cycle [15]. The Cyclin D1 promoter contains a typical T-cellfactor (Tcf)/lymphoid-enhancer-factor (LEF)-1 binding site and its activity is largely dependent on $\beta$-catenin [21]. Inspection of this region between -140 and -60 revealed one identified LEF-1-binding site [22]. To investigate whether the inhibitive effect of diazoxide upon the Cyclin D1 promoter was mediated by the LEF-1-binding site, we introduced site-directed mutagenesis into this LEF-1binding site on the pGL3 $(-420 /+18)$ reporter plasmid as previously described. It was found that the mutagenesis of this LEF-1-binding site abolished the effects of diazoxide on the Cyclin D1 promoter activity (Fig. 3b). In addition, a lower level of $\beta$-catenin was observed in extracts prepared from diazoxide-treated cells (Fig. 3c), suggesting that diazoxide may downregulate Cyclin D1 transcription via decreasing the $\beta$-catenin level. This conclusion was further supported in Fig. 3d, as the stimulation of Cyclin D1 promoter activity by transient transfection with $\beta$-catenin expression plasmids was largely blunted after diazoxide treatment.

Cyclin D1 Overexpression Abrogated DiazoxideInduced G1 Arrest

Because diazoxide downregulated Cyclin D1 expression, we wanted to determine whether Cyclin D1 played an important role in diazoxide-induced G1 arrest. To address this point, H1299 cells were transfected with control or GFP-tagged Cyclin D1 plasmid (Fig. 4a). Cyclin D1 overexpression abrogated diazoxide-induced G1 arrest by flow cytometry (Fig. 4b).

\section{Discussion}

In recent studies, the understanding of how diazoxide inhibited cell growth in hematologic cancers has greatly improved [5, 7, 9]. However, the mechanisms of the diazoxide-mediated growth inhibition in solid cancer are not well understood. The aim of our investigation was to elucidate the role of diazoxide in cell proliferation. In this report, we have described several observations in which the role of diazoxide in H1299 cell growth has been implicated by FACS assay, cell number, and Brdu incorporation. The results of our study suggest that diazoxide may be clinically useful in lung cancer patients as an adjuvant chemotherapeutic agent.

To elucidate the molecular mechanism of the role of diazoxide in $\mathrm{H} 1299$ cell growth, we have demonstrated that
A
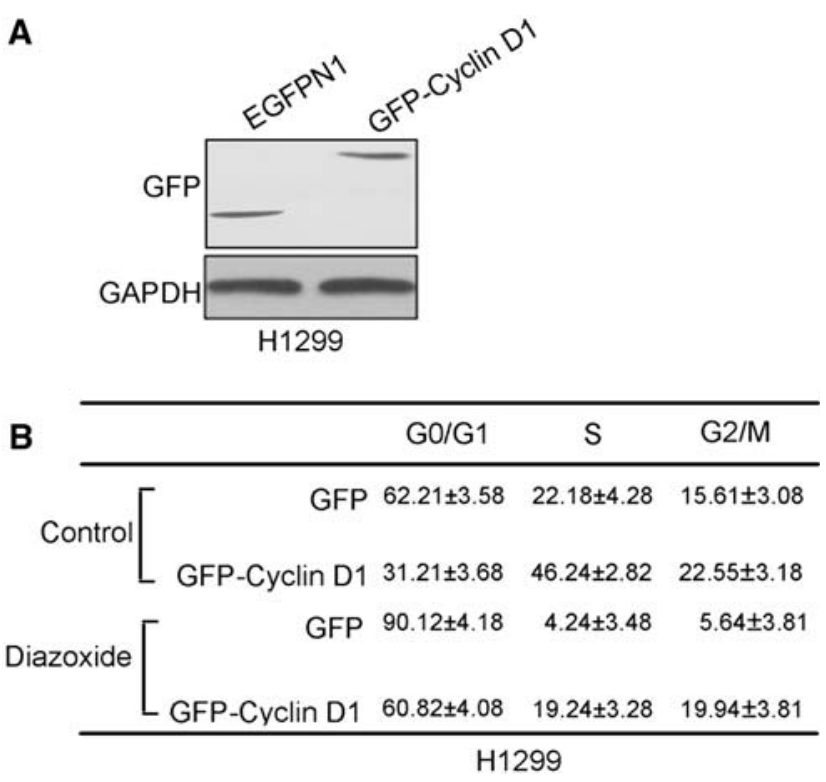

Fig. 4 Cyclin D1 overexpression abrogated diazoxide-induced G1 arrest. a H1299 cells were transiently transfected with control vector or GFP-tagged Cyclin D1 expression plasmid and cell extracts were analyzed by immunoblotting with an anti-GFP Ab. GAPDH served as a loading control. b Control or GFP-Cyclin D1 expression plasmid was transiently transfected into $\mathrm{H} 1299$ cells treated or not treated with diazoxide. At $24 \mathrm{~h}$ after transfection, the DNA content of cells was determined by propidium iodide staining and FACS analysis. The percentage of cells in each stage of the cell cycle is shown with each FACS profile

diazoxide decreases the protein and mRNA expression of Cyclin D1. Evidence of the oncogenic potential of Cyclin D1 is provided by studies with numerous models in which the elevated expression of Cyclin D1 shortens the G1 phase of the cell cycle and enhances malignant transformation $[14,23]$. An overexpression of Cyclin D1 blocked diazoxide-decreased H1299 cell growth, demonstrating that Cyclin D1 plays a major role in diazoxide-inhibited cell proliferation in H1299 cells. The limitations of our study are listed as follows: (1) All the experiments were performed with H1299 cells. Thus, it is important to show that the results obtained represent a general phenomenon and not a peculiarity of H1299 cells. (2) All the experiments were performed with $\mathrm{H} 1299$ cells in vitro. To further investigate the effect of diazoxide on lung cancer cell growth, the effect of diazoxide on H1299 cell growth in vivo should be performed using tumorigenicity assay.

Another interesting finding is that diazoxide downregulated Cyclin D1 transcription via reduction of $\beta$-catenin transcription factor. $\beta$-Catenin is a well-known DNAbinding nuclear protein that is widely expressed in tissues and binds to GC box motifs in promoters of many housekeeping genes and genes involved in growth regulation and cancer, including p21, caspase-8, Cyclin D1, and GalT V [24-26]. Biologically, $\beta$-catenin plays important roles in a 
wide variety of physiologic processes, including cell cycle, hormonal activation, apoptosis, angiogenesis, and oncogenesis $[24,27]$. To our knowledge, this is the first report that diazoxide decreased $\beta$-catenin expression, which contributed in diazoxide-reduced Cyclin D1 transcription, which elicited a new mechanism of diazoxide-contributed tumor development.

In summary, this work suggests that diazoxide reduced cell progression in H1299 cells via downregulation of Cyclin D1 transcription in a diazoxide-dependent manner, indicating that diazoxide is a very promising new drug for use in H1299 cells. The molecular mechanism of the downregulation of $\beta$-catenin mediated by diazoxide should be next investigated.

Acknowledgment We thank Dr. Liudan for providing the plasmid for Cyclin D1 promoter construct and pRL-CMV.

Open Access This article is distributed under the terms of the Creative Commons Attribution Noncommercial License which permits any noncommercial use, distribution, and reproduction in any medium, provided the original author(s) and source are credited.

\section{References}

1. Gok S, Vatansever S, Vural K, Sekuri C, Izanli A, Tezcan A, Cilaker S (2006) The role of ATP sensitive $\mathrm{K}^{+}$channels and of nitric oxide synthase on myocardial ischemia/reperfusioninduced apoptosis. Acta Histochem 108:95-104. doi:10.1016/ j.acthis.2006.01.005

2. Lou M, Chen Y, Ding M, Eschenfelder CC, Deuschl G (2006) Involvement of the mitochondrial ATP-sensitive potassium channel in the neuroprotective effect of hyperbaric oxygenation after cerebral ischemia. Brain Res Bull 69:109-116. doi:10.1016/ j.brainresbull.2005.11.009

3. O'Rourke B (2004) Evidence for mitochondrial $\mathrm{K}^{+}$channels and their role in cardioprotection. Circ Res 94:420-432. doi:10.1161/ 01.RES.0000117583.66950.43

4. Teshima Y, Akao M, Li RA, Chong TH, Baumgartner WA, Johnston MV, Marbán E (2003) Mitochondrial ATP-sensitive potassium channel activation protects cerebellar granule neurons from apoptosis induced by oxidative stress. Stroke 34:17961802. doi:10.1161/01.STR.0000077017.60947.AE

5. Eliseev RA, Vanwinkle B, Rosier RN, Gunter TE (2004) Diazoxide-mediated preconditioning against apoptosis involves activation of cAMP-response element-binding protein (CREB) and NFkappaB. J Biol Chem 279:46748-46754. doi:10.1074/jbc. M406217200

6. Huang Q, Bu S, Yu Y, Guo Z, Ghatnekar G, Bu M, Yang L, Lu B, Feng Z, Liu S, Wang F (2007) Diazoxide prevents diabetes through inhibiting pancreatic beta-cells from apoptosis via Bcl-2/ Bax rate and p38-beta mitogen-activated protein kinase. Endocrinology 148:81-91. doi:10.1210/en.2006-0738

7. Liu RG, Wang WJ, Song N, Chen YQ, Li LH (2006) Diazoxide preconditioning alleviates apoptosis of hippocampal neurons induced by anoxia-reoxygenation in vitro through up-regulation of Bcl-2/Bax protein ratio. Sheng Li Xue Bao 58:345-350

8. Lee YS (2004) Mechanism of apoptosis induced by diazoxide, a $\mathrm{K}^{+}$channel opener, in HepG2 human hepatoma cells. Arch Pharm Res 27:305-313
9. Ichinose M, Yonemochi H, Sato T, Saikawa T (2003) Diazoxide triggers cardioprotection against apoptosis induced by oxidative stress. Am J Physiol 284:H2235-H2241

10. Barendsen GW, Van Bree C, Franken NA (2001) Importance of cell proliferative state and potentially lethal damage repair on radiation effectiveness: implications for combined tumor treatments [review]. Int J Oncol 19:247-256

11. Bergsagel PL (2008) A kinder, gentler way: control of the proliferative tumor compartment, not cosmetic complete response, should be the goal of myeloma therapy. Leukemia 22:673-675. doi:10.1038/leu.2008.2

12. Gautschi O, Ratschiller D, Gugger M, Betticher DC, Heighway J (2007) Cyclin D1 in non-small cell lung cancer: a key driver of malignant transformation. Lung Cancer 55:1-14. doi:10.1016/ j.lungcan.2006.09.024

13. Kaye FJ (2002) RB and cyclin dependent kinase pathways: defining a distinction between RB and p16 loss in lung cancer. Oncogene 21:6908-6914. doi:10.1038/sj.onc.1205834

14. Knudsen KE, Diehl JA, Haiman CA, Knudsen ES (2006) Cyclin D1: polymorphism, aberrant splicing and cancer risk. Oncogene 25:1620-1628. doi:10.1038/sj.onc. 1209371

15. Tashiro E, Tsuchiya A, Imoto M (2007) Functions of cyclin D1 as an oncogene and regulation of cyclin D1 expression. Cancer Sci 98:629-635. doi:10.1111/j.1349-7006.2007.00449.x

16. Quante M, Heeg S, von Werder A, Goessel G, Fulda C, Doebele M, Nakagawa H, Beijersbergen R, Blum HE, Opitz OG (2005) Differential transcriptional regulation of human telomerase in a cellular model representing important genetic alterations in esophageal squamous carcinogenesis. Carcinogenesis 26:18791889. doi:10.1093/carcin/bgi153

17. Hilton TL, Li Y, Dunphy EL, Wang EH (2005) TAF1 histone acetyltransferase activity in Sp1 activation of the cyclin D1 promoter. Mol Cell Biol 25:4321-4332. doi:10.1128/MCB.25.10. 4321-4332.2005

18. Jiang J, Shen J, Wu T, Wei Y, Chen X, Zong H, Zhang S, Sun M, Xie J, Kong X, Yang Y, Shen A, Wang H, Gu J (2006) Downregulation of beta1,4-galactosyltransferase $\mathrm{V}$ is a critical part of etoposide-induced apoptotic process and could be mediated by decreasing Sp1 levels in human glioma cells. Glycobiology 16: 1045-1051. doi:10.1093/glycob/cw1027

19. Zhu X, Jiang J, Shen H, Wang H, Zong H, Li Z, Yang Y, Niu Z, Liu W, Chen X, Hu Y, Gu J (2005) Elevated beta1,4-galactosyltransferase I in highly metastatic human lung cancer cells. Identification of E1AF as important transcription activator. J Biol Chem 280:12503-12516. doi:10.1074/jbc.M413631200

20. Fukami-Kobayashi J, Mitsui Y (1998) The regulation of cyclin D1 expression in senescent human fibroblasts. Exp Cell Res 241:435-444. doi:10.1006/excr.1998.4079

21. Prasad CP, Gupta SD, Rath G, Ralhan R (2007) Wnt signaling pathway in invasive ductal carcinoma of the breast: relationship between beta-catenin, dishevelled and cyclin D1 expression. Oncology 73:112-117. doi:10.1159/000120999

22. Bartusel T, Schubert S, Klempnauer KH (2005) Regulation of the cyclin D1 and cyclin A1 promoters by B-Myb is mediated by Sp1 binding sites. Gene 351:171-180. doi:10.1016/j.gene.2005. 03.035

23. Roy PG, Thompson AM (2006) Cyclin D1 and breast cancer. Breast 15:718-727. doi:10.1016/j.breast.2006.02.005

24. Kavurma MM, Khachigian LM (2003) Sp1 inhibits proliferation and induces apoptosis in vascular smooth muscle cells by repressing p21WAF1/Cip1 transcription and cyclin D1-Cdk4p21WAF1/Cip1 complex formation. J Biol Chem 278:3253732543. doi:10.1074/jbc.M305650200

25. Aggarwal BB, Ichikawa $\mathrm{H}$ (2005) Molecular targets and anticancer potential of indole-3-carbinol and its derivatives. Cell Cycle 4:1201-1215 
26. Opitz OG, Rustgi AK (2000) Interaction between Sp1 and cell cycle regulatory proteins is important in transactivation of a differentiation-related gene. Cancer Res 60:2825-2830
27. Grinstein E, Jundt F, Weinert I, Wernet P, Royer HD (2002) Sp1 as $\mathrm{G} 1$ cell cycle phase specific transcription factor in epithelial cells. Oncogene 21:1485-1492. doi:10.1038/sj.onc.1205211 